\title{
Achieving Employability as We Age: The Role of Age and Achievement Goal Orientations on Learning and Employability
}

\author{
Dominik E. Froehlich ${ }^{1, *}$, Sandra Aasma ${ }^{2}$ and Simon Beausaert ${ }^{2}$ \\ 1 Centre for Teacher Education and Department of Education, University of Vienna, 1090 Vienna, Austria \\ 2 Department for Educational Research and Development, School of Business and Economics, \\ Maastricht University, 6200 MD Maastricht, the Netherland; s.aasma@maastrichtuniversity.nl (S.A.); \\ s.beausaert@maastrichtuniversity.nl (S.B.) \\ * Correspondence: dominik.froehlich@univie.ac.at
}

Received: 14 July 2020; Accepted: 28 July 2020; Published: 5 August 2020

\begin{abstract}
The aging workforce challenges companies to keep their aging employees employable in the workforce. This paper gives an indication as to which employees are more likely to be interested in further learning and employability. Specifically, the aim of this study was to investigate the role of chronological age and achievement goal orientations for informal and formal learning and employability. Data of 167 Austrian knowledge workers were gathered via electronic questionnaires to investigate the relationships between age, achievement goal orientations, learning activities, and employability using structural equation modeling. It was found that informal learning has a significant positive relation with several dimensions of employability. Furthermore, mastery-approach goal orientation also shows a significant positive relation with informal learning and employability. In addition, age had no significant relation with the achievement goal orientations. The paper stresses the need to consider characteristics other than chronological age, such as goal orientations, when considering employees' learning behavior and employability.
\end{abstract}

Keywords: chronological age; employability; formal learning; goal orientations; informal learning

\section{Introduction}

Because of higher life expectancy and lower birth-rates, the populations of most countries are aging (Börsch-Supan et al. 2014). To maintain the current standard of living, governments restructure their retirement policies; for instance, by increasing retirement age (Bassanini and Duval 2006). However, these actions are evidently not enough to keep employees in the workforce. Every year, the ratio between the non-working population and the working populations is increasing. This puts companies in the position where they become more and more dependent on their older employees. Thus, to keep a high level of performance and to keep up with fast-changing innovation and job requirements, human resource managers are challenged to maintain the competences and motivation of their older employees (Froehlich et al. 2015a).

One way for the employees to keep their skills up to date is to engage in learning activities. However, research has shown that older workers participate less in formal learning compared to younger workers (Raemdonck et al. 2015). One reason for this may be that older employees are less motivated to develop their skills (Froehlich et al. 2016). However, not all older workers are the same: with increasing age, individual differences also increase (Carstensen 2006). Thus, we propose that apart from employees' age, achievement goal orientations also influence employees' learning behavior and employability. Several studies have noted the importance of motivation for learning (Pintrich 1999) and employability (Van Emmerik et al. 2012). However, none of these articles have investigated the direct 
and mediating effects of achievement goal orientations on learning and employability. We narrow this gap by investigating the roles of age and achievement goal orientations for informal learning, formal learning, and employability. Additionally, the mediating role of learning on the relations between age and achievement goals and employability is tested. This information on the "micro level" will be useful to inform human resource management practices (Guest 2011). We test our research model (Figure 1) by conducting a cross-sectional survey study using structural-equation modeling.

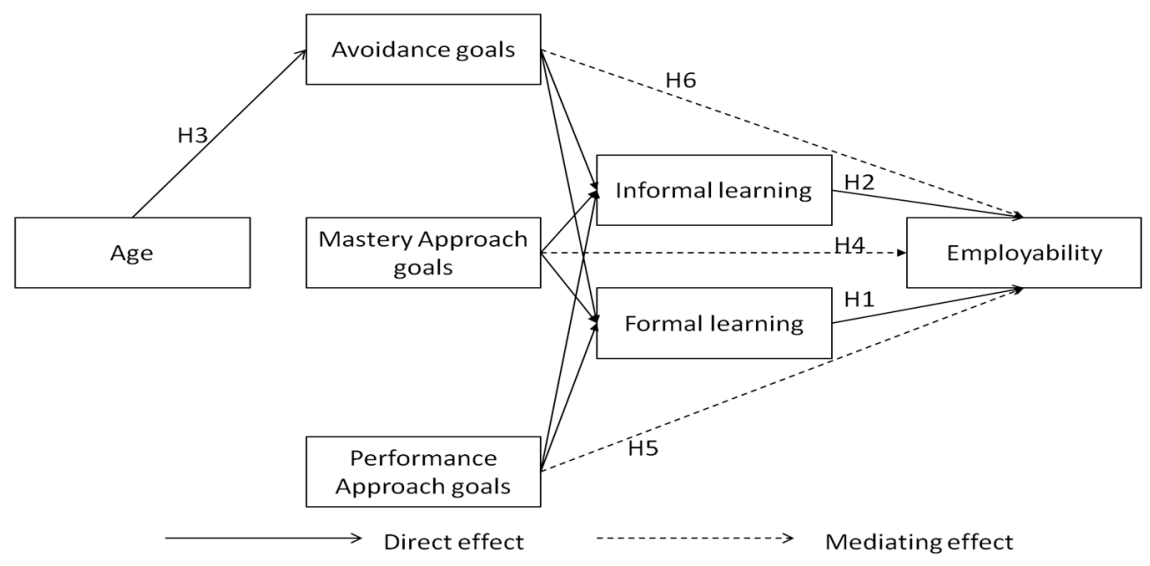

Figure 1. Overview of the research model.

\section{Theoretical Background}

\subsection{Employability}

Employability as a concept has developed over time alongside changes in job requirements and the transition from industrial to post-industrial work environment (Van der Heijde and Van der Heijden 2006). Current employability research focuses on individuals' attributes as a source for their employability (Froehlich et al. 2018): What competences do the employees have and develop? Hence we define employability as "the continuous fulfilling, acquiring or creating of work through the optimal use of competences" (Van der Heijde and Van der Heijden 2006, p. 453). Importantly, this definition is not concerned with actual employment or job search, although these concepts are, of course, dependent.

Van der Heijde and Van der Heijden (2006) proposed five interrelated competences (Froehlich et al. 2018) needed for continuous employability. Occupational expertise is defined as the domain-specific knowledge and skills needed for the job (Van der Heijden 2003). It is considered as an essential competence in times of low employment, since workers with obsolete occupational expertise are usually the first ones to be laid off (Boudreau et al. 2001). Anticipation and optimization reflect the workers' ability to adapt to future changes at the workplace and strive for the best work and career outcomes (Coetzee et al. 2015). Personal flexibility refers to the ability to adapt to changes at work. For example, people high in this competence adapt better to changes, such as mergers, reorganizations, or varying work requirements. Corporate sense means that employees need to identify themselves with organizational goals and accept the responsibility for the decision-making process (Chapman and Martin 1995). Moreover, corporate sense broadens the citizenship behavior to take part and perform in different teams within a company (Seibert et al. 2001). Last, balance means finding a trade-off between employers' and employees' interests. This balance should also be between employees' professional and private life (Van der Heijde and Van der Heijden 2006; Van der Heijden et al. 2018).

\subsection{Employability and Age}

Mixed arguments and empirical findings exist for the relationship between employability and age. On the one hand, for older workers, keeping up with the competences and skills to stay in the 
workforce seems to be more difficult than for younger workers (Ng and Feldman 2012). One of the major difficulties encountered by the older employees is the negative stereotypes directed towards them. Employers tend to see older workers as causing higher costs and being less productive. It is also thought that older workers show worse performance and less creativity and motivation to work (Ng and Feldman 2012). In addition, it has been found that the recruiters of a company were less likely to hire older workers, as they were seen as less adaptable to new technologies, less trainable, and less interested in technological change (Gringart et al. 2005). Hence, these stereotypes might lead to lower hiring rates, fewer opportunities for individual development, and more difficulties to stay employable for older workers. Importantly, these findings relate to subjective views on employability, which may be unrelated to the competences that we zero in on in this research.

A few studies found that employability may increase as employees get older. Froehlich et al. (2014a), for instance, found small positive effects of chronological age on occupational expertise and corporate sense and no effects for the other three dimensions. They argued that chronological age is a poor indicator by itself and that mediators need to be found that are more explanative of the relationship between age and employability. One such mediator was explicated by Aubert et al. (2006), who noted that in France, the older workforce represents a smaller fraction in companies in growth sectors. Apparently, older workers are rather found in declining sectors, which may lead to a loss in relevant competences and, hence, employability.

\subsection{Formal and Informal Learning}

Despite the negative stereotypes toward older workers, the graying population is creating a situation where employers have to find ways to retain their older workers. Thus, employers need to take care of the older employees' skills and competences to ensure that the workers stay productive (Van der Heijde and Van der Heijden 2006). Employees may develop the skills and competences through formal and informal learning (Froehlich et al. 2014a). Formal learning usually involves all training and development programs sponsored and endorsed by an organization (Manuti et al. 2015). It is characterized as structured and planned learning inside the organization, but outside of the working environment, usually in classroom-like settings. Formal learning is designed in such a way that set outcomes can be achieved (Manuti et al. 2015; Marsick and Watkins 2001; Van der Heijden et al. 2009). Formal learning is considered valuable in the job market through the formalized qualifications it often provides. For example, Van der Klink et al. (2014) found that formal job-related training predicted anticipation and optimization in academic staff members. Moreover, Van der Heijden et al. (2009) found that job-related formal learning enhances the employability of non-academic related workers of a university. These findings suggest that formal learning has a positive impact on employability.

Hypothesis 1. Employees' engagement in formal learning activities is positively related to their employability in terms of occupational expertise, anticipation and optimization, personal flexibility, corporate sense, and balance.

Informal learning is "any activity involving the pursuit of understanding, knowledge or skill which occurs outside the curricula of educational institutions, or the courses or workshops offered by educational or social agencies" (Livingstone 1999, p. 2). Informal learning is less structured and the worker is more accountable for it. It is usually embedded in daily work activities and may even happen unconsciously. Informal learning can involve different forms, such as mentoring, job rotation, job shadowing, feedback, and teamwork (Livingstone 1999). According to Garavan et al. (2002), informal learning at work is positively correlated with flexibility, employability, adaptability of learning to context, rapid transfer to practice, and the resolution of work-related problems through regular review of work practices and performance. Even positive effects of social informal learning have been established (Beausaert et al. 2016). Van der Klink et al. (2014) found that informal learning predicts anticipation and optimization, personal flexibility, and corporate sense. Hence, we expect a positive relationship between informal learning and competence-based employability. 
Hypothesis 2. Employees' engagement in informal learning activities is positively related to their employability in terms of occupational expertise, anticipation and optimization, personal flexibility, corporate sense, and balance.

\subsection{Achievement Goal Orientations}

Achievement goals' conceptual core lies in competence, where competence is defined in terms of the standard that is used for the performance evaluation (Elliot and McGrego 2001). Competence can be evaluated in different ways: whether one has mastered the task or acquired the understanding; whether there is an improvement of the knowledge; or how one performs in relation to others (Elliot and McGrego 2001). Elliot and McGrego (2001) merged the first two competence evaluations, since they both deal with self-improvement, rather than comparing oneself with others; this is also the perspective we adopt in this article. Elliot and McGrego (2001) proposed the two-by-two goal achievement framework that distinguishes mastery and performance goal orientations and avoidance and approach directions. According to the framework, people with mastery goal orientation take themselves as a reference point; they strive to become better to improve themselves. By contrast, people with performance goal orientation compare themselves with others and their main goal is to be better than others. Avoidance or maintenance orientation means that people do not pursue new challenges and aim to maintain their current state. By contrast, people with an approach orientation are looking for new challenges to develop their knowledge, skills, and abilities (Elliot and McGrego 2001).

According to life span theory, as people age, the focus changes from approach orientation to maintenance orientation so as to prevent losses (Baltes 1987). Such change takes place due to the decreasing mental, biological, and social resources across a person's life span. Carstensen (2006) argued that the less time people have in their life, the more likely they are to invest in emotional contacts, rather than cognitively stimulating contacts. Hence, they invest more time in activities and skills that they already have and do not try to approach new challenges. In sum, older people are more likely to have avoidance goals. Ebner et al. (2006) investigated the goal orientations of people across different ages and found that older people tend to have stronger focus towards maintenance and loss prevention, whereas younger people report primarily approach goals. In line with this theory and similar empirical evidence, we hypothesize that older workers are more likely to have avoidance goals.

Hypothesis 3. Employees' chronological age is positively related to having an avoidance goal orientation.

Other studies have found support for a relation between several processes known to enhance learning, such as intrinsic motivation, interest, better self-regulation, deeper strategy use, and mastery-approach goal orientation (Ford et al. 1998; Harackiewicz et al. 2004). Moreover, mastery-approach goals are associated with more positive affective experiences, such as feelings of challenge in response to difficulties (Elliott and Dweck 1988). Rakoczy et al. (2013) investigated the moderating effect of mastery-approach goal orientation on the relation between feedback and the perceived usefulness of feedback on students. They found that participants who had a mastery-approach goal orientation were more likely to benefit from the feedback. In addition, Ranellucci et al. (2013) found that participants who reported having a strong mastery-approach goal focus engaged in deeper information processing. In-depth information processing can lead to increased learning. Other studies suggested a positive relationship between mastery-approach orientation and formal learning. For example, Dishon-Berkovits (2014) found that mastery-approach goals result in higher academic achievement levels in high-school students. Furthermore, Dinger et al. (2013) found that students' mastery-approach goals were predictive of their intrinsic motivation and thus of their academic achievement. No studies directly investigated the effects of mastery-goal orientation on employability, although several studies found positive effects of mastery-approach goal orientation on learning. 
Hypothesis 4. Employees' mastery-approach orientation is positively related to their employability in terms of occupational expertise, anticipation and optimization, personal flexibility, corporate sense, and balance via informal and formal learning.

Contradicting evidence has been found about performance-approach goal orientation. This goal orientation is associated with negative effects, such as anxiety (Daniels et al. 2009), and with positive effects, such as academic achievement and deeper learning strategies (Diseth and Kobbeltvedt 2010). Van der Rijt et al. (2012) noted a positive effect in multinational corporations between performance-approach orientation and feedback-seeking among financial experts. They explained these findings as linked to the nature of accounting, finance, and control, where the incentive system is dominant and gaining a favorable appraisal is important. Chadwick and Raver (2012) argued that performance-approach goal orientation is mainly related to exploitative learning processes. Such processes are based on knowledge that was previously gained. Hence, individuals with performance-approach goals are motivated to perform in ways that make them appear competent. Moreover, they engage in learning activities if they need to demonstrate competence or outperform others.

In sum, many studies have noted positive relations between performance-approach goals and different learning activities; several studies have also shown negative relationships with variables such as anxiety (Daniels et al. 2009). However, no studies have demonstrated the effects between performance goal orientation and employability. We believe that due to the positive effects of performance-approach goal orientation on learning, it will also have positive effects on employability.

Hypothesis 5. Being performance-approach orientated positively affects employability dimensions in terms of occupational expertise, anticipation and optimization, personal flexibility, corporate sense, and balance via formal and informal learning.

There are few studies on the effects of mastery-avoidance goals and performance-avoidance on learning. Van Yperen et al. (2009) noted that since mastery-avoidance goals have only recently begun to receive attention from researchers, there are still no consistent patterns. Chadwick and Raver (2012) noted that performance-avoidance goals hinder explorative and exploitative learning processes. Thus, employees with performance-avoidance goals focus their energy on avoiding negative outcomes. In line with Kahneman (1973) cognitive theories of attention, Chadwick and Raver (2012) reasoned that individuals do not have enough cognitive resources to engage in learning activities. Moreover, such individuals might avoid learning activities out of fear that these activities would expose their incompetence and they might not select the relevant information needed for learning because of their cognitive overload (Sutcliffe and Weick 2008; VandeWalle 2003). Evidently, both avoidance goals have similar effects on learning activities and employability. Therefore, we propose that both avoidance goals are negatively related to learning activities and employability:

Hypothesis 6. Mastery-avoidance and performance-avoidance goal orientations negatively affect employability dimensions in terms of occupational expertise, anticipation and optimization, personal flexibility, corporate sense, and balance via formal and informal learning.

\section{Materials and Methods}

\subsection{Procedure and Participants}

We sent electronic questionnaires to 215 randomly selected employees of two Austrian knowledge-intensive organizations. The first organization is an IT consultancy ( $\mathrm{n}=77$; response rate $=72 \%$ ) and the second is a non-profit consultancy in the field of international trade and legal advisory $(n=90$; response rate $=83 \%$ ). The total sample consists of 167 participants, of which 
86 were female $(52 \%)$. The respondents were 18 to 59 years old (mean $=40.80$ years, standard deviation $=9.88$ years). Ninety-three $(56 \%)$ of the respondents had a higher education degree.

\subsection{Instruments}

The five dimensions of employability were measured using Van der Heijde and Van der Heijden (2006) scale. All items included were answered on a 5-point Likert scale $(1=$ "almost never" to $5=$ "very often"; for sample items and reliabilities see Table 1).

Table 1. Description and internal reliability of the scales.

\begin{tabular}{llll}
\hline Scale & Items & $\alpha$ & Sample Item \\
\hline $\begin{array}{l}\text { Mastery-approach goal } \\
\text { orientation }\end{array}$ & 3 & 0.58 & I desire to completely master my work. \\
\hline $\begin{array}{l}\text { Performance-approach } \\
\text { goal orientation }\end{array}$ & 3 & 0.91 & $\begin{array}{l}\text { My aim at work is to get a better performance } \\
\text { rating than most of my other colleagues. }\end{array}$ \\
\hline $\begin{array}{l}\text { Avoidance goal } \\
\text { orientation }\end{array}$ & 6 & 0.69 & $\begin{array}{l}\text { I am often concerned that I may not learn all that } \\
\text { there is to learn at my work. }\end{array}$ \\
\hline $\begin{array}{l}\text { Informal learning } \\
\text { Occupational expertise }\end{array}$ & 15 & 0.77 & $\begin{array}{l}\text { I participate in project groups to discuss } \\
\text { work-related problems. }\end{array}$ \\
\hline $\begin{array}{l}\text { Anticipation and } \\
\text { optimization }\end{array}$ & 8 & 0.92 & $\begin{array}{l}\text { In general, I am competent to distinguish main } \\
\text { issues from side issues and to set priorities. }\end{array}$ \\
\hline Personal flexibility & 8 & 0.77 & $\begin{array}{l}\text { I consciously devote attention to applying my } \\
\text { newly acquired knowledge and skills. }\end{array}$ \\
\hline Corporate sense & 7 & 0.80 & $\begin{array}{l}\text { I support the operational processes within } \\
\text { my organization. }\end{array}$ \\
\hline Balance & 9 & 0.83 & \begin{tabular}{l} 
My work and private life are evenly balanced. \\
\hline
\end{tabular} \\
\hline
\end{tabular}

Formal learning was measured by asking the participants about the number of days spent in formal learning activities in the previous year. To receive more accurate responses, they were requested to answer this question for a range of different learning activities, such as attendance of conferences or seminars. From these measures, the sum of hours spent in formal learning activities was calculated.

Froehlich et al. (2017) social work-related informal learning scale was used to gauge informal learning. The scale measures different types of informal learning_information-seeking, feedback-seeking from a supervisor, feedback-seeking from colleagues, and help-seeking. The scale is answered on a 5-point Likert scale $(1=$ "almost never" to $5=$ "very often"). As we were not interested in different types of informal learning, we decided to combine the different informal learning scales into one variable.

To measure different goal orientations, we used an achievement goal orientation questionnaire developed by Elliot and McGrego (2001). The scale consists of 12 items answered on a 5-point Likert scale $\left(1=\right.$ "not at all true of $m e^{\prime \prime}$ to $5=$ "very true of $\left.m e^{\prime \prime}\right)$. Items measuring mastery-avoidance and performance-avoidance were aggregated to a single avoidance goal orientation scale to increase the reliability (Elliot and Thrash 2002).

Additionally, respondents indicated their chronological age in an open question.

\subsection{Analyses}

We tested the hypotheses using structural equation modeling in Mplus version 7.0 software. Single items were aggregated into parcels, which were then used as indicators of latent factors in the analyses (Little et al. 2002). The data do not contain any missing values; maximum likelihood estimation was used. We determined model fit by investigating the chi square $(\chi 2)$ statistic, the root 
mean square error of approximation (RMSEA, acceptable if $\leq 0.08$ ), and the comparative fit index (CFI, acceptable if $\geq 0.90$ ) (e.g., Browne and Cudeck 1993; Hooper et al. 2008).

\section{Results}

The structural model revealed an acceptable model fit: Although the $\chi 2$ statistic was statistically significant $(\chi 2=289.10, p<0.01)$, which indicates poor model fit, the more robust CFI and RMSEA indicators suggested that the model fit the data sufficiently well (CFI $=0.90$, RMSEA $=0.08)$.

We did not find any statistically significant relation between formal learning and employability (B $\leq 0.001$, not significant). Thus, Hypothesis 1 was not supported. Conversely, we found a positive relation between informal learning and anticipation and optimization $(\mathrm{B}=0.18, p \leq 0.05)$, personal flexibility $(\mathrm{B}=0.23, p<0.01)$, corporate sense $(\mathrm{B}=0.24, p<0.01)$, and balance $(\mathrm{B}=0.25, p<0.05)$. This partially supports Hypothesis 2.

For Hypothesis 3 we proposed a positive relationship between employees' chronological age and their avoidance goal orientation. However, the data showed a negative link between both concepts $(\mathrm{B}=-0.01, p<0.05)$. Hypothesis 3 , therefore, was not supported.

For what concerns the effects of the different goal orientations (Hypotheses 4-6), the data showed a direct link of mastery-approach goal orientation to occupational expertise $(\mathrm{B}=0.15, p<0.01)$ and indirect relationships via informal learning to anticipation and optimization $(\mathrm{B}=0.07, p<0.05)$, personal flexibility $(B=0.08, p<0.01)$, corporate sense $(B=0.09, p<0.01)$, and balance $(B=0.09$, $p<0.05)$. In contrast to what we have proposed in Hypothesis 5 , we only observed a direct relationships between performance approach goal orientation and anticipation and optimization $(\mathrm{B}=0.15, p<0.01)$ and no indirect effects. Lastly, the data revealed negative direct relationships between avoidance goal orientations and occupational expertise $(\mathrm{B}=-0.19, p<0.01)$ and anticipation and optimization $(\mathrm{B}=-0.18, p<0.01)$.

\section{Discussion}

In this article, we argued that chronological age and achievement goal orientations affect the engagement in learning activities and, subsequently, employability. In testing the model, we observed positive effects of informal learning on anticipation and optimization, corporate sense, personal flexibility, and balance. In line with this, Van der Klink et al. (2014) noted that informal learning is positively related to three employability dimensions, namely anticipation and optimization, personal flexibility, and corporate sense. Other researchers reported similar results (Froehlich et al. 2014a; Froehlich et al. 2015b; Van der Heijden et al. 2009; Van der Klink et al. 2014), finding that informal learning from others has positive effects on employability.

In addition, we hypothesized different achievement goal orientations to have a significant relation with informal and formal learning, as well as employability. Although there have been studies about different achievement goals and learning behavior (e.g., Dinger et al. 2013; Diseth and Kobbeltvedt 2010; Hulleman et al. 2010) there have been no studies investigating achievement goals and their influence on employability. We found evidence that mastery-approach goal orientation relates significantly positively and directly to occupational expertise, and indirectly via informal learning to anticipation and optimization, personal flexibility, corporate sense, and balance. This means that people who have mastery-approach goal orientation tend to engage more in informal learning activities and thus increase their employability. Furthermore, we found evidence that employees having performance-approach goal orientations tend to score higher on anticipation and optimization. This means that people having performance-approach goal orientation are better prepared for future changes at the workplace. As expected, we found that people with avoidance goal orientations tend to score lower on occupational expertise and anticipation and optimization. This means that employees having avoidance goal orientations have lower occupational expertise and are less prepared for future changes in the workplace. 
This study contributes novel empirical findings that help understand how employees develop their employability. Future research may help increase the robustness of the findings by addressing some of the limitations of this study. For example, we did not find any relation between age and learning activities. This may be attributable to the sample of knowledge-intensive workers. We can assume that due to fast-changing job requirements, employees in consultancies, independent of their age, have to be motivated to learn in order to succeed in their job (Horwitz et al. 2003). Moreover, the inclusion of other covariates may be warranted, such as one's family situation, psychosocial experience, and health. These variables might be considered to get more accurate interpretation of age (e.g., Peeters et al. 2008; Sterns and Miklos 1995). Furthermore, since all the variables were measured by using self-reported surveys, the measurement of employability, learning activities, and achievement goal orientation measures might suffer from common method variance (Chang et al. 2010). However, all instruments have shown high construct validity (Conway and Lance 2010), which limits the probability of such a bias. Still, future research may include different sources of data, such as measures by employers or colleagues; it may study the complex process of becoming more employable at more levels simultaneously (Shen et al. 2018), or integrate qualitative and quantitative data (Creswell and Plano-Clark 2017; Schoonenboom et al. 2018). Data could also be improved in terms of the range of samples taken. The given data do not allow to make broad generalizations; data collected in multiple and more diverse context will be instrumental in applying the findings to a broader range of settings and enhance external validity.

The findings are also of relevance to professionals in international human resource management. First, we have found that to foster employees' learning and employability, mastery-approach goals should be enhanced. For instance, Muis and Edwards (2009) mentioned that the fear of failure will predict changes in performance-approach goals, whereas anxiety will predict changes in performance-avoidance goals. This means that in order to diminish avoidance goals, a learning climate should be set up in which mistakes can be made. For example, in a warm learning climate there is facilitation, appreciation, and no error-avoidance. Therefore, employees are more likely to have positive perceptions of organizational policies and practices aimed at facilitating, rewarding, and supporting employee learning behavior (Nikolova et al. 2014). Second, it was already noted by Muis and Edwards (2009) that task interest will predict changes in mastery-approach goals, meaning that in order to enhance mastery-approach goals, employees' personal preferences-such as career development, responsibilities, or task interest-should be taken into account. In addition, Fryer and Elliot (2007) noted that goal change can be enhanced from encountering the achievement task (which may be more or less difficult than one anticipated) and from receiving performance feedback (which may be above or below one's expectations). This implies that to change employees' goals, one would need to set up achievement tasks and provide constant performance feedback. These suggestions are corroborated by the study findings presented in this article. Third, we suggest that in order to maintain an employable and competent workforce, employees should be encouraged to engage in informal learning. This may include measures such as investing in building favorable learning cultures (Davis et al. 2014; Froehlich et al. 2014b; Marsick and Watkins 2003), reflecting about individual approaches to learning (Bernsen et al. 2009; Froehlich 2017), and optimizing the social learning networks in the workplace (Borgatti and Cross 2003; Cross et al. 2001; Froehlich et al. 2017; Froehlich and Messmann 2017).

Author Contributions: Conceptualization, D.E.F. and S.A.; Methodology, D.E.F. and S.A.; Software D.E.F.; Validation D.E.F., S.A., S.B.; Analysis D.E.F. and S.A., Data curation, D.E.F. and S.B., writing, D.E.F., S.A., S.B.; supervision D.E.F. and S.B. All authors have read and agreed to the published version of the manuscript.

Funding: This research received no external funding.

Conflicts of Interest: The authors declare no conflict of interest. 


\section{References}

Aubert, Patrick, Eve Caroli, and Muriel Roger. 2006. New technologies, organisation and age: Firm-level evidence. The Economic Journal 116: F73-93. [CrossRef]

Baltes, Paul B. 1987. Theoretical propositions of life-span developmental psychology: On the dynamics between growth and decline. Developmental Psychology 23: 611-26. [CrossRef]

Bassanini, Andrea, and Romain Duval. 2006. Employment Patterns in OECD Countries: Reassessing the Role of Policies and Institutions. OECD Economics Department Working Papers No. 486. Pairs: OECD Publishing (NJ1).

Beausaert, Simon A. J., Dominik E. Froehlich, Christelle Devos, and Philip Riley. 2016. Effects of support on stress and burnout in school principals. Educational Research 58: 347-65. [CrossRef]

Bernsen, Paula, Mien S. R. Segers, and Harm H. Tillema. 2009. Learning under Pressure: Learning Strategies, Workplace Climate, and Leadership Style in the Hospitality Industry. International Journal of Human Resource Development and Management 9: 358-73. [CrossRef]

Borgatti, Stephen P., and Rob Cross. 2003. A Relational View of Information Seeking and Learning in Social Networks. Management Science 49: 432-45. [CrossRef]

Börsch-Supan, Axel, Klaus Härtl, and Alexander Ludwig. 2014. Aging in Europe: Reforms, International Diversification, and Behavioral Reactions. American Economic Review 104: 224-29. [CrossRef]

Boudreau, John W., Wendy R. Boswell, and Timothy A. Judge. 2001. Effects of Personality on Executive Career Success in the United States and Europe. Journal of Vocational Behavior 58: 53-81. [CrossRef]

Browne, Michael W., and Robert Cudeck. 1993. Alternative Ways of Assessing Model Fit. In Testing Structural Equation Models. Edited by Kenneth A. Bollen and John S. Long. Newbury Park: Sage Publications, pp. 136-62.

Carstensen, Laura L. 2006. The Influence of a Sense of Time on Human Development. Science 312: 1913-15. [CrossRef]

Chadwick, Ingrid C., and Jana L. Raver. 2012. Motivating Organizations to Learn: Goal Orientation and Its Influence on Organizational Learning. Journal of Management 41: 957-86. [CrossRef]

Chang, Sea-Jin, Arjen Van Witteloostuijn, and Lorraine Eden. 2010. From the Editors: Common method variance in international business research. Journal of International Business Studies 41: 178-84. [CrossRef]

Chapman, Gary M., and John F. Martin. 1995. Computerized business games in engineering education. Computers E Education 25: 67-73. [CrossRef]

Coetzee, Melinde, Nadia Ferreira, and Ingrid L. Potgieter. 2015. Assessing employability capacities and career adaptability in a sample of human resource professionals. SA Journal of Human Resource Management 13: 9. [CrossRef]

Conway, James M., and Charles E. Lance. 2010. What Reviewers Should Expect from Authors Regarding Common Method Bias in Organizational Research. Journal of Business and Psychology 25: 325-34. [CrossRef]

Creswell, John W., and Vicki L. Plano-Clark. 2017. Designing and Conducting Mixed Methods Research. Thousand Oaks: SAGE Publications.

Cross, Robert L., Andrew Parker, Laurence Prusak, and Stephen P. Borgatti. 2001. Knowing What We Know: Supporting Knowledge Creation and Sharing in Social Networks. Organizational Dynamics 30: 100-20. [CrossRef]

Daniels, Lia M., Robert H. Stupnisky, Reinhard Pekrun, Tara L. Haynes, Raymond P. Perry, and Nancy E. Newall. 2009. A Longitudinal Analysis of Achievement Goals: From Affective Antecedents to Emotional Effects and Achievement Outcomes. Journal of Educational Psychology 101: 948-63. [CrossRef]

Davis, Kate M., Sarahlouise White, and Matthew Stephenson. 2014. The influence of workplace culture on nurses' learning experiences: A systematic review protocol of qualitative evidence. The JBI Database of Systematic Reviews and Implementation Reports 11: 45. [CrossRef]

Dinger, Felix C., Oliver Dickhäuser, Birgit Spinath, and Ricarda Steinmayr. 2013. Antecedents and consequences of students' achievement goals: A mediation analysis. Learning and Individual Differences 28: 90-101. [CrossRef]

Diseth, Age, and Therese Kobbeltvedt. 2010. A mediation analysis of achievement motives, goals, learning strategies, and academic achievement. The British Journal of Educational Psychology 80: 671-87. [CrossRef]

Dishon-Berkovits, Miriam. 2014. A study of motivational influences on academic achievement. Social Psychology of Education 17: 327-42. [CrossRef] 
Ebner, Natalie C., Alexandra M. Freund, and Paul B. Baltes. 2006. Developmental changes in personal goal orientation from young to late adulthood: From striving for gains to maintenance and prevention of losses. Psychology and Aging 21: 664-78. [CrossRef]

Elliot, Andrew J., and Holly A. McGrego. 2001. A 2x2 Achievement Goal Framework. Journal of Personality and Social Psychology 80: 501-19. [CrossRef] [PubMed]

Elliot, Andrew J., and Todd M. Thrash. 2002. Approach-avoidance motivation in personality: Approach and avoidance temperaments and goals. Journal of Personality and Social Psychology 82: 804-18. [CrossRef] [PubMed]

Elliott, Elaine S., and Carol S. Dweck. 1988. Goals: An approach to motivation and achievement. Journal of Personality and Social Psychology 54: 5-12. [CrossRef]

Ford, J. Kevin, Eleanor M. Smith, Daniel A. Weissbein, Stanley M. Gully, and Eduardo Salas. 1998. Relationships of goal orientation, metacognitive activity, and practice strategies with learning outcomes and transfer. Journal of Applied Psychology 83: 218-33. [CrossRef]

Froehlich, Dominik E. 2017. 'Older Managers' Informal Learning in Knowledge-Intensive Organizations: Investigating the Role of Learning Approaches among Austrian Bank Managers. The International Journal of Human Resource Management 28: 399-416. [CrossRef]

Froehlich, Dominik E., and Gerhard Messmann. 2017. The Social Side of Innovative Work Behavior: Determinants of Social Interaction during Organizational Innovation Processes. Business Creativity and the Creative Economy 3: 31-41. [CrossRef]

Froehlich, Dominik E., Simon A. J. Beausaert, Mien S. R. Segers, and Maike Gerken. 2014a. Learning to Stay Employable. Career Development International 19: 508-25. [CrossRef]

Froehlich, Dominik E., Mien S. R. Segers, and Piet Van den Bossche. 2014b. Informal Workplace Learning in Austrian Banks: The Influence of Learning Approach, Leadership Style, and Organizational Learning Culture on Managers' Learning Outcomes. Human Resource Development Quarterly 25: 29-57. [CrossRef]

Froehlich, Dominik E., Simon A. J. Beausaert, and Mien S. R. Segers. 2015a. Age, Employability and the Role of Learning Activities and Their Motivational Antecedents: A Conceptual Model. The International Journal of Human Resource Management 26: 2087-101. [CrossRef]

Froehlich, Dominik E., Simon A. J. Beausaert, and Mien S. R. Segers. 2015b. Great Expectations: The Relationship between Future Time Perspective, Learning from Others, and Employability. Vocations and Learning 8: 213-27. [CrossRef]

Froehlich, Dominik E., Simon A. J. Beausaert, and Mien S. R. Segers. 2016. Aging and the Motivation to Stay Employable. Journal of Managerial Psychology 31: 756-70. [CrossRef]

Froehlich, Dominik E., Simon A. J. Beausaert, and Mien S. R. Segers. 2017. Development and Validation of a Scale Measuring Approaches to Work-Related Informal Learning. International Journal of Training and Development 21: 130-44. [CrossRef]

Froehlich, Dominik E., Mingyang Liu, and Beatrice I. J. M. Van der Heijden. 2018. Work in Progress: The Progression of Competence-Based Employability. Career Development International 23: 230-44. [CrossRef]

Fryer, James W., and Andrew J. Elliot. 2007. Stability and change in achievement goals. Journal of Educational Psychology 99: 700-14. [CrossRef]

Garavan, Thomas N., Michael Morley, Patrick Gunnigle, and David McGuire. 2002. Human resource development and workplace learning: Emerging theoretical perspectives and organisational practices. Journal of European Industrial Training 26: 60-71. [CrossRef]

Gringart, Eyal, Edward Helmes, and Carig P. Speelman. 2005. Exploring Attitudes Toward Older Workers among Australian Employers: An Empirical Study. Journal of Aging and Social Policy 17: 85-103. [CrossRef]

Guest, David E. 2011. Human resource management and performance: Still searching for some answers. Human Resource Management Journal 21: 3-13. [CrossRef]

Harackiewicz, Judith M., Amanda M. Durik, and Kenneth E. Barron. 2004. Multiple Goals, Optimal Motivation, and the Development of Interest. In Social Motivation. Edited by Joseph P. Forgas, Kipling D. Williams and Simon M. Laham. Cambridge: Cambridge University Press, pp. 21-39. [CrossRef]

Hooper, Daire, Joseph Coughlan, and Michael R. Mullen. 2008. Structural Equation Modelling: Guidelines for Determining Model Fit. Electronic Journal of Business Research Methods 6: 53-60.

Horwitz, Frank M., Chan T. Heng, and Hesan A. Quazi. 2003. Finders, keepers? Attracting, motivating and retaining knowledge workers. Human Resource Management Journal 13: 23-44. [CrossRef] 
Hulleman, Chris S., Sheree M. Schrager, Shawn M. Bodmann, and Judith M. Harackiewicz. 2010. A meta-analytic review of achievement goal measures: Different labels for the same constructs or different constructs with similar labels? Psychological Bulletin 136: 422-49. [CrossRef]

Kahneman, Daniel. 1973. Attention and Effort. Englewood Cliffs: Prentice-Hall.

Little, Todd D., William A. Cunningham, Golan Shahar, and Keith F. Widaman. 2002. To Parcel or Not to Parcel: Exploring the Question, Weighing the Merits. Structural Equation Modeling 9: 151-73. [CrossRef]

Livingstone, David W. 1999. Exploring the icebergs of adult learning: Findings of the first Canadian survey of informal learning practices. Canadian Journal for the Study of Adult Education 13: 49-72.

Manuti, Amelia, Serafina Pastore, Anna F. Scardigno, Maria L. Giancaspro, and Daniele Morciano. 2015. Formal and informal learning in the workplace: A research review. International Journal of Training and Development, 1-17. [CrossRef]

Marsick, Victoria J., and Karen E. Watkins. 2001. Informal and Incidental Learning. New Directions for Adult and Continuing Education 2001: 25-34. [CrossRef]

Marsick, Victoria J., and Karen E. Watkins. 2003. Demonstrating the Value of an Organization's Learning Culture: The Dimensions of the Learning Organization Questionnaire. Advances in Developing Human Resources 5: 132-51. [CrossRef]

Muis, Krista R., and Ordene Edwards. 2009. Examining the stability of achievement goal orientation. Contemporary Educational Psychology 34: 265-77. [CrossRef]

Ng, Thomas W.H., and Daniel C. Feldman. 2012. Evaluating Six Common Stereotypes About Older Workers with Meta-Analytical Data. Personnel Psychology 65: 821-58. [CrossRef]

Nikolova, Irina, Joris Van Ruysseveldt, Hans De Witte, and Karen Van Dam. 2014. Learning climate scale: Construction, reliability and initial validity evidence. Journal of Vocational Behavior 85: 258-65. [CrossRef]

Peeters, Maria, Hetty van Emmerik, Dorien Kooij, Annet de Lange, Paul Jansen, and Josje Dikkers. 2008. Older workers' motivation to continue to work: Five meanings of age: A conceptual review. Journal of Managerial Psychology 23: 364-94. [CrossRef]

Pintrich, Paul R. 1999. The role of motivation in promoting and sustaining self-regulated learning. International Journal of Educational Research 31: 459-70. [CrossRef]

Raemdonck, Isabel, Simon A. J. Beausaert, Dominik E. Froehlich, Nané Kochoian, and Caroline Meurant. 2015. Age related changes in learning and employability. In Aging Workers and the Employee-Employer Relationship. Edited by Denise Rosseau, Dorien T. A. M. Kooij and P. Matthijs Bal. Cham: Springer International Publishing, pp. 163-84.

Rakoczy, Katrin, Brigit Harks, Eckhard Klieme, Werner Blum, and Jan Hochweber. 2013. Written feedback in mathematics: Mediated by students' perception, moderated by goal orientation. Learning and Instruction 27: 63-73. [CrossRef]

Ranellucci, John, Krista R. Muis, Melissa Duffy, Xihui Wang, Lavanya Sampasivam, and Gina M. Franco. 2013. To master or perform? Exploring relations between achievement goals and conceptual change learning: Achievement goals and conceptual change. British Journal of Educational Psychology 83: 431-51. [CrossRef] [PubMed]

Schoonenboom, Judith, R. Burke Johnson, and Dominik E. Froehlich. 2018. Combining Multiple Purposes of Mixing Within a Mixed Methods Research Design. International Journal of Multiple Research Approaches 10: 271-82. [CrossRef]

Seibert, Scott E., Maria L. Kraimer, and J. Michael Crant. 2001. What do proactive people do? A longitudinal model linking proactive personality and career success. Personnel Psychology 54: 845-74. [CrossRef]

Shen, Jie, Jake G. Messersmith, and Kaifeng Jiang. 2018. Advancing human resource management scholarship through multilevel modeling. The International Journal of Human Resource Management 29: 227-38. [CrossRef]

Sterns, Hl, and Sm Miklos. 1995. The aging worker in a changing environment: Organizational and individual issues. Journal of Vocational Behavior 47: 248-68. [CrossRef]

Sutcliffe, Kathleen M., and Karl E. Weick. 2008. Information Overload Revisited. The Oxford Handbook of Organizational Decision Making. Oxford: Oxford University Press. [CrossRef]

Van der Heijde, Claudia M., and Beatrice I.J.M. Van der Heijden. 2006. A competence-based and multidimensional operationalization and measurement of employability. Human Resource Management 45: 449-76. [CrossRef]

Van der Heijden, Beatrice I.J.M. 2003. Organisational influences upon the development of occupational expertise throughout the career. International Journal of Training and Development 7: 142-65. [CrossRef] 
Van der Heijden, Beartrice I.J.M., Jo Boon, Marcel R. Van der Klink, and Ely Meijs. 2009. Employability Enhancement through Formal and Informal Learning: An Empirical Study among Dutch Non-Academic University Staff Members. International Journal of Training and Development 13: 19-37. [CrossRef]

Van der Heijden, Beatrice I.J.M., Guy Notelaers, Pascale Peters, Jol M. M. Stoffers, Annet H. De Lange, Dominik E. Froehlich, and Claudia M. Van der Heijde. 2018. Development and validation of the short-form employability five-factor instrument. Journal of Vocational Behavior 106: 236-48. [CrossRef]

Van der Klink, Marcel R., Beatrice I. J. M. Van der Heijden, Jo Boon, and Shahron Williams van Rooij. 2014. Exploring the contribution of formal and informal learning to academic staff member employability. Career Development International 19: 337-56. [CrossRef]

Van der Rijt, Janine, Piet Van den Bossche, Margje W. J. Van de Wiel, Mien S. R. Segers, and Wim H. Gijselaers. 2012. The role of individual and organizational characteristics in feedback-seeking behaviour in the initial career stage. Human Resource Development International 15: 283-301. [CrossRef]

Van Emmerik, Hetty, Bert Schreurs, Nele De Cuyper, I. M. Jawahar, and Maria C.W. Peeters. 2012. The route to employability: Examining resources and the mediating role of motivation. Career Development International 17: 104-19. [CrossRef]

Van Yperen, Nico W., Andrew J. Elliot, and Frederik Anseel. 2009. The influence of mastery-avoidance goals on performance improvement. European Journal of Social Psychology 39: 932-43. [CrossRef]

VandeWalle, Don. 2003. A goal orientation model of feedback-seeking behavior. Human Resource Management Review 13: 581-604. [CrossRef]

(C) 2020 by the authors. Licensee MDPI, Basel, Switzerland. This article is an open access article distributed under the terms and conditions of the Creative Commons Attribution (CC BY) license (http://creativecommons.org/licenses/by/4.0/). 